\title{
The Effect of an Inhaled Corticosteroid on Glucose Control in Type 2 Diabetes
}

\author{
John L. Faul, MD; Sandra R. Wilson, PhD; James W. Chu, MD; \\ James Canfield, BS; and Ware G. Kuschner, MD
}

Objective: To determine the effect of inhaled corticosteroid (ICS) therapy on glucose control in adults with type 2 diabetes mellitus and coexisting asthma or chronic obstructive pulmonary disease (COPD).

Design: A prospective randomized, double-blind, double-dummy placebo-controlled, crossover investigation of inhaled steroids and oral leukotriene blockers.

Setting: A United States Department of Veterans Affairs Health Care System outpatient setting.

Participants: Adults with type 2 diabetes and asthma or COPD.

Methods: Subjects $(n=12)$ were randomized to receive either inhaled fluticasone propionate ( $440 \mu \mathrm{g}$ twice daily) and oral placebo, or inhaled placebo and oral montelukast ( $10 \mathrm{mg} /$ day). After 6 weeks, subjects were switched to the opposite therapy for 6 weeks. The primary outcome measure was the change in the percentage of glycosylated hemoglobin (\% HbAlc) at 6 weeks relative to the baseline value.

Results: Ten patients completed the study. The difference between the mean within-subject changes in $\% \mathrm{HbAlc}$ associated with 6-week periods of fluticasone and the mean changes associated with montelukast therapy was small but statistically significant (mean difference $=0.25 ; P<0.025$ ). Neither fluticasone nor oral montelukast therapy for 6 weeks led to a significantly different mean \% HbAlc compared with the relevant baseline (mean differences $=0.1 \mathrm{I}$ and -0.14 , respectively).

Conclusion: The absence of a clinically significant within-subject difference in the changes in \%HbAlc associated with fluticasone versus oral montelukast therapy, or between either therapy or baseline does not warrant recommending changes in therapy for asthma or diabetes in patients with these co-morbid conditions. However, we suggest that clinicians carefully monitor blood glucose control when diabetic patients initiate ICS, especially with higher dosages.

Keywords: Asthma; COPD; Diabetes mellitus; Inhaled steroid

$\mathrm{T}$ ype 2 diabetes mellitus, chronic obstructive pulmonary disease (COPD), and asthma are increasing in prevalence worldwide. Many patients with type 2 diabetes have an indication to use inhaled corticosteroids (ICS) for coexisting asthma or COPD. ICS have been shown to have systemic effects, but their effect on glucose metabolism in patients with type 2 diabetes has not been well defined. Although considered a safe therapy, there are concerns about the systemic effects of ICS, including bone formation in children ${ }^{1,2}$ and cataract development in adults. ${ }^{3-5}$ Additionally, several studies suggest ICS can suppress the function of the hypothalamic pituitary adrenal axis. ${ }^{6-10}$ While such adverse effects have been detected in research studies, they are thought not to be clinically important. A significant increase $(1.0 \%)$ in glycosylated hemoglobin (\%HbAlc) and persistent glucosuria has been reported previously in a patient with type 2 diabetes mellitus and asthma who used inhaled fluticasone propionate (FP) at a high dose $(2 \mathrm{mg} /$ day $) .{ }^{11}$ It is unclear whether lower doses of ICS might disturb glucose metabolism.

In order to assess the effect of anti-asthma therapy on glucose control in patients with type 2 diabetes, we performed a double-blind, double-dummy, randomized, placebo-controlled,
Corresponding Author:

Ware G. Kuschner, MD, U.S. Department of Veterans Affairs, Palo Alto Health Care System, 380I Miranda Avenue, Mail Code: IIIP, Palo Alto, CA, 94304, Tel: 650-493-5000, ext.63544, Fax:650-852-3276,Email: kuschner@stanford.edu

\section{Disclosure:}

Merck \& Co., USA provided funding support for the investigation. Merck played no role in the study design, in the collection, analysis, or interpretation of the data, or in the preparation of the manuscript. Merck did not review the final manuscript and provided no comments to the authors regarding the preparation of the manuscript. There were no confidentiality agreements with Merck regarding the study results.

None of the investigators has any financial relationship to disclose.
Received: September II, 2008

Revised: January 15, 2009

Accepted: January 21, 2009

doi: $|0.3| 2 \mid / \mathrm{cmr} .2009 .824$ 
cross-over investigation analyzing patients treated with inhaled FP, $440 \mu \mathrm{g}$ twice daily, and the oral leukotriene receptor antagonist, montelukast. The purpose of this investigation was to determine whether moderate doses of inhaled FP $(<1 \mathrm{mg} /$ day) adversely affected glucose metabolism in patients with type 2 diabetes.

We compared effects of inhaled FP on glucose metabolism with montelukast, a leukotriene receptor antagonist with no known effects on glucose metabolism, as the control condition. Leukotriene receptor antagonists are widely used in asthma. They are not indicated in the treatment of COPD, but appear to lead to improved lung function in some patients. ${ }^{12,13}$ Our primary outcome measure was the within-subject difference in $\% \mathrm{HbA} 1 \mathrm{c}$ after 6 weeks use of ICS compared with 6 weeks use of oral montelukast. Percent $\mathrm{HbA} 1 \mathrm{c}$ is a reliable and clinically important marker of glucose control in diabetes mellitus. ${ }^{14-17}$

\section{METHODS}

\section{Overview}

We performed a 12-week randomized, double-blind, double-dummy placebo-controlled, crossover study of inhaled FP (440 $\mu \mathrm{g}$ twice daily) versus oral montelukast (10 mg/day) in non-smoking patients with type 2 diabetes mellitus and stable asthma or COPD. The study design is outlined in figure 1 . This study was reviewed and approved by the Stanford
University Administrative Panel on Human Subjects in Medical Research. It was also reviewed and approved by the Veterans Affairs Palo Alto Health Care System (VAPAHCS) Research and Development Committee.

\section{Study Participants and Study Setting}

Subjects were recruited utilizing advertisements posted on the grounds of the United States Department of VAPAHCS, which operates three hospital-based divisions and six community-based outpatient clinics delivering health care to veterans of the United States military services. All subjects were administered informed consent. Subjects were screened if they were outpatient veterans who reported a physician diagnosis of diabetes that did not require management with insulin, and a physician diagnosis of either asthma or COPD. Participants with type 2 diabetes managed with oral hypoglycemic medication or without medication (diet-controlled) were eligible.

\section{Inclusion Criteria}

Patients were included if they (1) were age 18 years or greater, (2) had type 2 diabetes confirmed by a fasting plasma glucose $>126 \mathrm{mg} / \mathrm{dl}$ on a screening visit, and (3) had a physician diagnosis of either asthma or COPD confirmed by electronic medical record review.

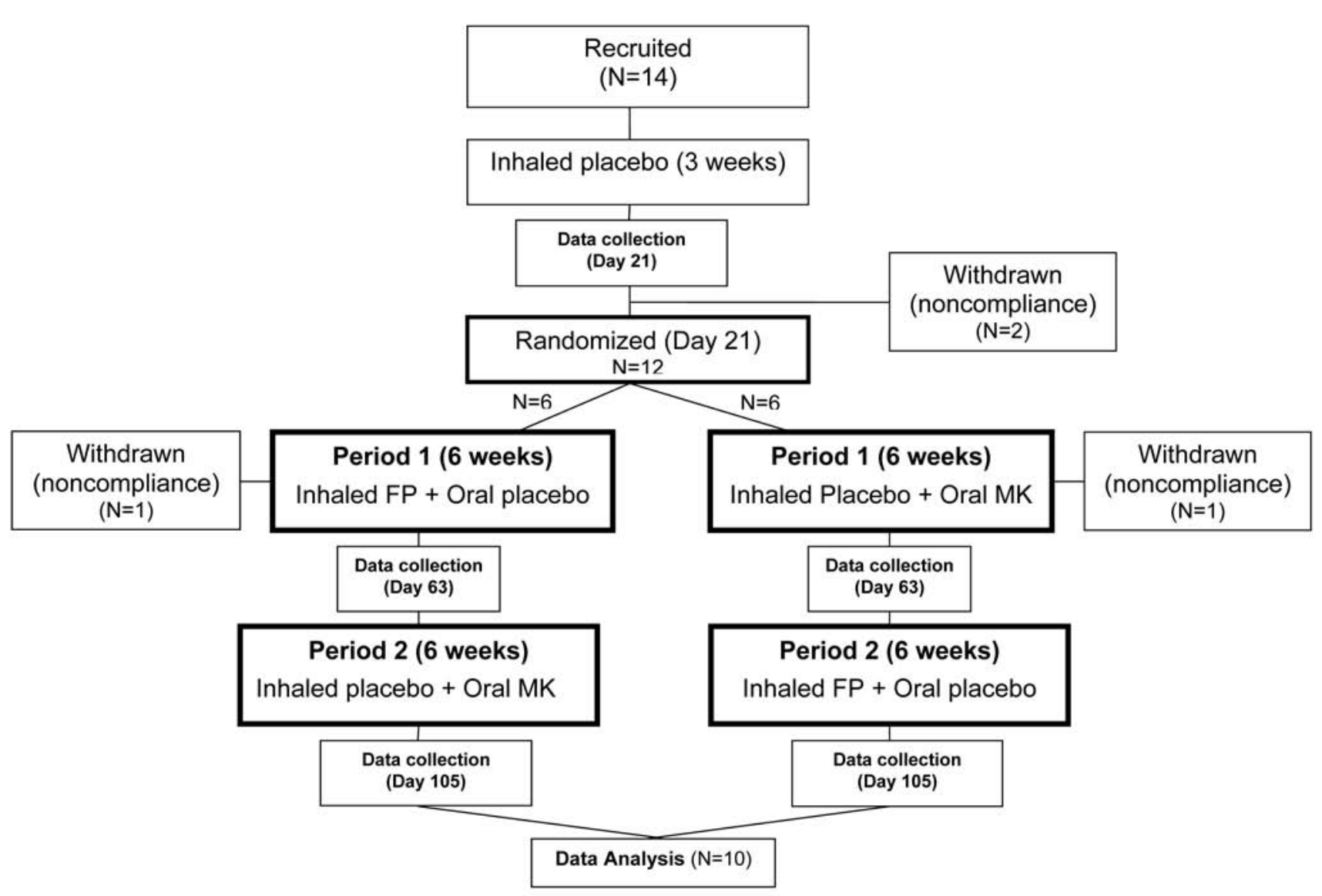

Figure 1. Study design. A randomized, double-blind, placebo-controlled, crossover study. 


\section{Exclusion Criteria}

Patients were excluded if they had (1) used tobacco within 6 months of enrollment, (2) a history of exacerbation of asthma or COPD within 3 months of enrollment, (3) current insulin use, (4) use of systemic corticosteroids or ICS, leukotriene receptor antagonists, or theophylline within 1 month of enrollment, (5) inability to read and complete a diary card, (6) inability to perform spirometry, peak expiratory flow testing, and (7) inability to use a metered dose inhaler with spacer.

\section{Interventions}

After enrollment, participants completed a 3-week run-in period during which they took a placebo inhaler, two puffs twice daily. On day 21, the initial baseline data were obtained including a blood draw for $\% \mathrm{HbAlc}$ testing and the randomization was performed in coordination with the research pharmacy at VAPAHCS. A random number generator was used to randomize subjects, in a double-blinded fashion, to receive either inhaled FP $(880 \mu \mathrm{g} /$ day or 2 puffs twice daily of a $220 \mu \mathrm{g}$ /actuation metered dose inhaler) with a spacer and oral placebo tablets, or inhaled placebo, two puffs twice daily, and oral montelukast $(10 \mathrm{mg} /$ day $)$ for 6 weeks. After 6 weeks, subjects crossed over to the opposite treatment limb. After the second 6-week treatment period, the study was completed (figure 1). At the conclusion of both treatment periods, the research pharmacy disclosed to the investigators the treatment assignment order for each of the study participants.

The placebo medications were supplied by Merck \& Co., USA (tablets) and GlaxoSmithKline, USA (metered-dose inhalers) and were identical in appearance to montelukast and $\mathrm{FP}$, respectively. All subjects were instructed in the use of a spacer device in combination with their metered dose inhalers. Albuterol (GlaxoSmithKline, USA) via metered dose inhaler was prescribed on an as-needed basis. Other prescribed medications, including cholesterol lowering agents and oral hypoglycemic agents, were not changed during the study. At the time of randomization and after each 6-week treatment period, participants underwent spirometry (Sensor Medics, Yorba Linda, CA) both before and again 20 minutes after the administration of nebulized albuterol. Subjects also had a fasting blood draw for $\% \mathrm{HbAlc}$. Six weeks was chosen as a treatment period because clinically significant increases in $\% \mathrm{HbAlc}$ after 6 weeks of therapy with very high-dose $(2 \mathrm{mg} /$ day) inhaled corticosteroids had been previously reported. ${ }^{11}$ Six subjects who also took oral hypoglycemic medication recorded once daily self-monitoring of blood glucose (SMBG) measured after an overnight fast. The others who controlled their diabetes with diet only did not perform daily SMBG. Fasting serum insulin was measured in all subjects.

Participants were contacted by telephone once weekly during the study to ensure drug compliance and to assess for adverse events. Subjects were instructed to measure and record their daily peak expiratory flow rate (PEFR) using a hand-held Mini-Wright flow meter (Clement Clarke International, Essex, UK). The study safety limit was specified to be an acute fall in PEFR by more than $20 \%$ or a SMBG measurement $>300 \mathrm{mg} / \mathrm{dl}$.

\section{Objectives}

The primary objective was to determine whether inhaled FP at a dose of $440 \mu \mathrm{g}$ twice daily affects glucose control in patients with type 2 diabetes who have coexistent asthma or COPD. The primary outcome measure was within-subject difference in $\% \mathrm{HbA} 1 \mathrm{c}$ after 6 weeks of fluticasone versus 6 weeks of oral montelukast therapy. The secondary outcome was the within-subject change in $\% \mathrm{HbAlc}$ from baseline after each type of therapy.

\section{Outcome Measures}

The study was conducted as a crossover design with no washout period between therapies. Percent HbAlc was measured on days 63 (at the end of treatment period 1), and on day 105 (at the end of treatment period 2) by high performance liquid chromatography (Bio-Rad Variant, Bio-Rad Laboratories, USA). Baseline $\% \mathrm{HbA} 1 \mathrm{c}$ for period 1 was the day 21 value; baseline for period 2 was the day 63 value.

Since only six subjects measured SMBG, we used SMBG as a safety rather than an outcome measure in those patients. Weekly mean SMBG was determined by averaging the daily values within each 7-day period. SMBG was measured using the Accu-chek (Roche Diagnostics, USA) glucose meter system. Other safety measures included lung function (forced expiratory volume in one second $\left[\mathrm{FEV}_{1}\right]$, the forced expiratory volume in 1 second to forced vital capacity ratio $\left[\mathrm{FEV}_{1} / \mathrm{FVC}\right]$, the forced expiratory flow during the middle $50 \%$ of the forced expiratory maneuver $\left[\mathrm{FEF}_{25-75}\right]$, and the presence of a bronchodilator response defined as an increase in $\mathrm{FEV}_{1}$ over baseline spirometry 15 minutes after administration of 2 puffs $[180 \mu \mathrm{g}]$ of albuterol by metered dose inhaler) and change in fasting serum insulin. Weight was measured with clothes on and shoes off at each study visit.

\section{Sample Size}

We anticipated a mean increase of 1.0 in $\% \mathrm{HbAlc}$ after fluticasone treatment based on a previous report. ${ }^{11}$ The standard deviation (SD) of \% HbAlc in patients with type 2 diabetes ranges from 0.27 among those with good glucose control and 0.44 among patients with fair control to 1.73 with poor control. ${ }^{18}$ Since no previous investigations have studied the effect of ICS on glucose control, we estimated the SD of the change in \%HbA1c from baseline would be 1.0 , with no change as a result of oral montelukast therapy. Using these values, we estimated a sample size of 16 patients with a crossover study design would be necessary to detect a statistically significant difference between the therapies utilizing a two-tailed $t$ test $(\alpha=0.05, \beta=0.20)$.

\section{Data Collection}

Baseline demographic, lung function, and $\% \mathrm{HbA} 1 \mathrm{c}$ and fasting blood glucose data were obtained just prior to randomization (table 1) and at 6 and 12 weeks after initiation of therapy. 
Table 1. Baseline characteristics $(n=10){ }^{\star}$

\begin{tabular}{|c|c|c|}
\hline Measure & Mean & Range \\
\hline Age & 64 years & $52-76$ years \\
\hline Glycosylated hemoglobin & $6.8 \%$ & $5.3-7.7 \%$ \\
\hline Fasting glucose ${ }^{\dagger}$ & $146 \mathrm{mg} / \mathrm{dl}$ & $94-219 \mathrm{mg} / \mathrm{dl}$ \\
\hline Serum insulin & $16 \mu \mathrm{U} / \mathrm{ml}$ & $4-38 \mu \mathrm{U} / \mathrm{ml}$ \\
\hline Duration of diabetes & 8 years & 2-30 years \\
\hline Body mass index & $33 \mathrm{~kg} / \mathrm{m}^{2}$ & $23-43 \mathrm{~kg} / \mathrm{m}^{2}$ \\
\hline $\mathrm{FEV}_{1} \%$ predicted & $63 \%$ & $25-114 \%$ \\
\hline $\mathrm{FEV}_{1} / \mathrm{FVC}$ & $50 \%$ & $34-89 \%$ \\
\hline $\mathrm{FEF}_{25-75} \%$ predicted & $49 \%$ & $12-110 \%$ \\
\hline Bronchodilator response & $10 \%$ & $8-23 \%$ \\
\hline \multicolumn{3}{|c|}{$\begin{array}{l}\text { * A total of } 12 \text { subjects were randomized; two withdrew within } 3 \text { weeks of } \\
\text { randomization and, as a result, lacked follow-up data and could not be } \\
\text { included in the analysis. }\end{array}$} \\
\hline \multicolumn{3}{|c|}{$\begin{array}{l}\text { † To convert values for glucose to } \mathrm{mmol} / \mathrm{l} \text {, multiply by } 0.055 \text {. } \\
\mathrm{FEF}_{25-75} \text {, forced expiratory maneuver; } \mathrm{FEV}_{1} \text {, forced expiratory volume in } 1 \\
\text { second; FVC, forced vital capacity. }\end{array}$} \\
\hline
\end{tabular}

Subjects subsequently recorded daily PEFR in diary cards; those subjects performing SMBG also recorded results in diary cards. Investigators were blinded to the treatment limb throughout the study.

\section{Statistical Analyses}

We included patients with COPD and asthma together in one experimental population. The difference between the mean within-subject changes in $\% \mathrm{HbA1c}$ from the relevant baseline to the end of 6 weeks of fluticasone treatment and the mean changes associated with montelukast was evaluated using the paired student's $t$ test, as were the significance of the changes between baseline and follow-up for each medication. The presence of a carryover effect also was assessed using student's $t$ test by comparing the observed baseline to 6-week changes in the subjects who received inhaled FP before oral montelukast with those of the subjects who received these treatments in the reverse order. Data are presented as means (SD) unless otherwise indicated. Calculations were performed with the use of Microsoft Excel (Redmond, WA) software.

\section{RESULTS}

Fourteen male subjects were recruited, screened, and enrolled in the investigation over a 6-month period. Two subjects were excluded from the study prior to randomization due to non-compliance with the research protocol; 12 were randomized. Two randomized subjects were excluded on day 21 of the first treatment period (one from each study arm) because of non-compliance. Ten subjects completed the investigation, and their baseline characteristics are presented in table 1. Five subjects had a physician diagnosis of asthma and five had COPD. There was no drop-out for exacerbation of asthma or COPD. There was no study-related adverse event.
The mean within-subject baseline to 6-week difference in $\% \mathrm{HbA} 1 \mathrm{c}$ was significantly greater after treatment with inhaled FP than after treatment with oral montelukast therapy (mean within-subject difference $=0.25 ; P<0.025$ ) (table 2 ), but the mean difference was smaller than the $0.5 \%$ difference that would be considered clinically relevant and smaller than the $1.0 \%$ value the sample size was originally designed to detect. The fact that this difference was statistically significant with only 5 subjects per group is due to the lower-than-anticipated variance in the within-subject, within-treatment differences.

After 6 weeks of inhaled FP use, the mean (SD) change in $\% \mathrm{HbA} 1 \mathrm{c}$ was $+0.11(0.17)$, compared with baseline. After 6 weeks of oral montelukast therapy, the mean (SD) change in $\% \mathrm{HbA} 1 \mathrm{c}$ was $-0.14(0.26)$ (table 2). During inhaled FP therapy, 7 subjects had an increase in \%HbAlc over their baseline value, 2 had a reduction, and 1 was unchanged. During oral montelukast therapy, 6 subjects had a reduction in $\% \mathrm{HbA} 1 \mathrm{c}, 2$ had an increase, and 2 were unchanged relative to their baseline value (figure 2).

Interestingly, of the six subjects who used oral hypoglycemic agents and who measured daily SMBG, four were randomly allocated to receive inhaled FP with oral placebo in period 1 and two were randomly allocated to receive oral montelukast and inhaled placebo in period 1. After 6 weeks, inhaled FP was associated with an increase in mean (SD) weekly average of fasting SMBG of 18 (12) $\mathrm{mg} / \mathrm{dl}$, compared with baseline. Oral montelukast therapy was associated with a reduction in mean (SD) weekly average of fasting SMBG of 23 (26) $\mathrm{mg} /$ $\mathrm{dl}$, compared to baseline. The difference in the change in the weekly average of SMBG between therapies was significant at week $5(P<0.02)$ and week 6 of therapy $(P<0.05)$.

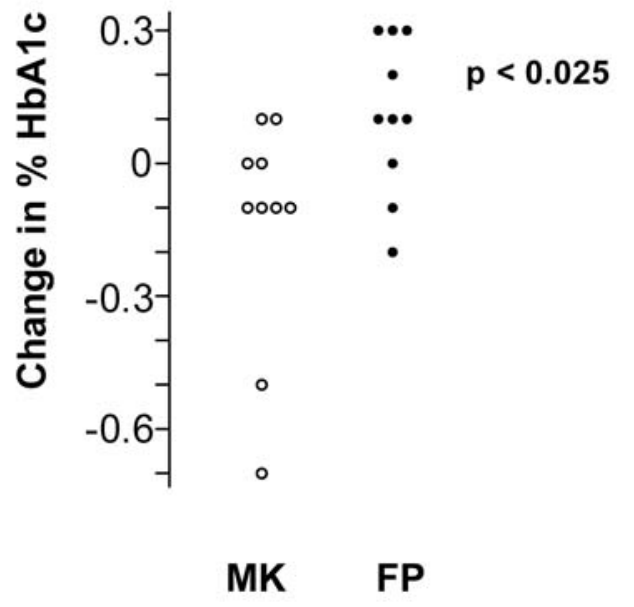

Figure 2. Changes in percent glycosylated hemoglobin (\%HbA1c) from baseline. The open circles represent changes in \% HbA1c after 6 weeks of oral montelukast (MK) $(10 \mathrm{mg} /$ day). The closed circles represent changes in \% $\mathrm{HbA} 1 \mathrm{c}$ after 6 weeks of inhaled fluticasone propionate (FP) $(440 \mu \mathrm{g}$ twice daily). The $P$-value denotes the level of significance using a two-tailed $t$ test for differences between therapies. 
Table 2. Changes in metabolic control from baseline to the end of 6 weeks of therapy with inhaled FP ( $880 \mu \mathrm{g} /$ day $)$ and oral montelukast (10 mg/day) $(n=10) .{ }^{*}$ Data are presented as mean ( \pm standard deviation).

\begin{tabular}{lcccccccc}
\hline & \multicolumn{3}{c}{ Change from baseline after $\mathbf{6}$ weeks of therapy } & & \multicolumn{2}{c}{ Inhaled FP - oral montelukast } \\
\cline { 2 - 5 } & \multicolumn{2}{c}{ Inhaled FP } & \multicolumn{2}{c}{ Oral montelukast } & & \multicolumn{2}{c}{ In } \\
\cline { 2 - 5 } Variable & Change & $\%$ change & Change & $\%$ change & & Difference & $\%$ change & $\boldsymbol{P}$-value \\
\hline Weight $(\mathrm{kg})$ & $-0.9(2.7)$ & $-0.7(2.9)$ & $0(2.5)$ & $0(2.2)$ & & $-0.9(3.2)$ & $-0.7(3.8)$ & 0.54 \\
HbA1c $(\%)$ & $0.11(0.17)$ & $1.7(2.6)$ & $-0.14(0.26)$ & $-2.1(3.6)$ & & $0.25(0.29)$ & $3.8(4.3)$ & 0.025 \\
Insulin $(\mu \mathrm{Units} / \mathrm{ml})$ & $-1(7)$ & $15(71)$ & $-0.3(5)$ & $18(69)$ & & $-0.7(9)$ & $-3(122)$ & 0.83 \\
\hline
\end{tabular}

* A total of 12 subjects were randomized; two withdrew within 3 weeks of randomization and, as a result, lacked follow-up data and could not be included the analysis. $P$-values were determined by a two-tailed $t$ test for differences between therapies.

$\mathrm{FP}$, fluticasone propionate; HbA1c, glycosylated hemoglobin.

Post hoc analysis revealed the presence of a carryover effect $(P<0.02)$ that resulted in an underestimate of the change in $\% \mathrm{HbAlc}$ associated with inhaled FP therapy. There was no significant difference between therapies in terms of weight or serum insulin (table 2).

\section{DISCUSSION}

This is the first (albeit a small) prospective, randomized double-blind, placebo-controlled investigation to compare the effects of anti-asthma therapies on glucose metabolism in patients with type 2 diabetes mellitus and co-existing COPD or asthma. We hypothesized that patients with type 2 diabetes mellitus would experience a significantly greater mean $\% \mathrm{HbA} 1 \mathrm{c}$ after 6 weeks of FP administered by metered dose inhaler in a divided daily dose of $880 \mu \mathrm{g}$, compared with their baseline value, than after 6 weeks of oral montelukast therapy $(10 \mathrm{mg} /$ day $)$. The reduction in $\% \mathrm{HbAlc}$ and SMBG during montelukast therapy is consistent with a study effect and does not likely represent a pharmacological effect of the medication. The magnitude of the difference in changes in $\% \mathrm{HbAlc}$ between the two treatments is small relative to the accepted $0.5 \%$ considered to be a clinically relevant change. However, this difference may have been underestimated, as suggested by the observation of a significant carryover effect among subjects who crossed over from inhaled FP to oral montelukast compared with the opposite arm. The fact that the 6-week (42 day) period of fluticasone therapy was less than the half-life of a red blood cell (60 days) may also contribute to underestimation of the treatment difference. Glycation is non-linear over time and occurs over the whole lifespan of a red blood cell. Lung function was stable during the study period indicating the observed changes in glucose control were not attributable to exacerbations of asthma or COPD.

The observed treatment-related changes in $\% \mathrm{HbAlc}$ in this study are consistent with our prior report of hyperglycemia and glucosuria in an asthmatic patient with type 2 diabetes mellitus who took very high doses of inhaled FP at a dose of $2 \mathrm{mg}$ /day; however, the mean increase resulting from FP therapy, relative to the individual's own baseline, is substantially smaller than in that individual case. ${ }^{11}$ Reduced insulin sensitivity, without hyperglycemia, has been demonstrated in non-diabetic, non-asthmatic adults who took inhaled beclomethasone dipropionate $(1 \mathrm{mg} / \text { day for } 4 \text { weeks })^{19}$ and asthmatic (non-diabetic) children who took inhaled budesonide $\left(0.8 \mathrm{mg} / \mathrm{m}^{2} /\right.$ day for 4 weeks $){ }^{20}$ In one uncontrolled study, reductions in serum insulin concentrations were observed in non-diabetic patients who took high-dose inhaled steroids for unstable asthma. ${ }^{21}$ The authors concluded that this effect was more likely due to a fall in endogenous catecholamines that accompanied the resolution of unstable disease, rather than an effect of inhaled steroid therapy. In another study, 14 normal subjects and 10 non-asthmatic patients with diet-controlled type 2 diabetes mellitus took inhaled placebo for 2 weeks followed by inhaled beclomethasone dipropionate ( $2 \mathrm{mg} /$ day) for 2 weeks. ${ }^{22}$ Inhaled glucocorticoid therapy did not significantly alter glucose tolerance tests and insulin levels after 2 weeks. However, \%HbA1c and SMBG were not measured, and the authors comment that an effect might have been observed with prolonged therapy, which also was not explored in the present study. In addition, beclomethasone is less potent than fluticasone as assessed by gene transactivation and transrepression. ${ }^{23}$

Large intervention studies in patients with type 1 and type 2 diabetes mellitus have demonstrated that intensive glycemic control reduces the onset and delays the progression of microvascular complications, including retinopathy, nephropathy, and neuropathy. ${ }^{16,24-28}$ Risk reductions in various outcomes ranged between $25 \%$ to $75 \%$, and these reductions appeared to be related to the duration and severity of hyperglycemia. ${ }^{24,27,28}$ The United Kingdom Prospective Diabetes Study demonstrated a continuous relationship between glycemic control and various complications, such that for a reduction in $\% \mathrm{HbA} 1 \mathrm{c}$ of 1.0 , there was a $35 \%$ reduction in the risk of complications, a $25 \%$ reduction in diabetes-related deaths, a 7\% decrease in all-cause mortality and an $18 \%$ reduction in combined fatal and non-fatal myocardial infarction. ${ }^{24,27}$ Accordingly, modest deterioration in glucose control attributable to anti-asthma therapy, even on the order of the differences observed in this study, could contribute to the development of diabetic complications in at-risk populations.

\section{CONCLUSION}

This study demonstrates that moderately high-dose (ICS for the treatment of asthma or COPD is associated with small disturbances in glucose control after a relatively brief period 
of therapy in diabetic subjects relative to oral montelukast therapy. The changes are detectable, but smaller than those that typically would be considered clinically relevant in individual patients, and hence would not merit a change or stoppage of therapy. Asthma, COPD, and diabetes are very common diseases that are increasing in prevalence. Clinicians should carefully monitor control of blood glucose when diabetic patients initiate ICS and may need to intensify diabetes treatment when ICS are administered at high dosages. In addition, research is needed to confirm whether small changes in diabetic control are associated with moderate-high dose ICS, on the order of those observed here, and to determine whether these changes are associated with a significant increase in diabetic complications at the population level.

\section{ACKNOWLEDGMENTS}

The authors thank Phillip Lavori, PhD, Stanford University School of Medicine, for his assistance with statistical analyses.

\section{REFERENCES}

1. Boot AM, de Jongste JC, Verberne AA, Pols HA, de Muinck Keizer-Schrama SM. Bone mineral density and bone metabolism of prepubertal children with asthma after long-term treatment with inhaled corticosteroids. Pediatr Pulmonol 1997;24:379-384.

2. Allen DB. Effects of inhaled steroids on growth, bone metabolism, and adrenal function. Adv Pediatr 2006;53:101-110.

3. Jick SS, Vasilakis-Scaramozza C, Maier WC. The risk of cataract among users of inhaled steroids. Epidemiology 2001;12:229-234.

4. Cumming RG, Mitchell P, Leeder SR. Use of inhaled corticosteroids and the risk of cataracts. N Engl J Med 1997;337:8-14.

5. Uboweja A, Malhotra S, Pandhi P. Effect of inhaled corticosteroids on risk of development of cataract: a meta-analysis. Fundam Clin Pharmacol 2006;20:305-309.

6. Lipworth BJ. Systemic adverse effects of inhaled corticosteroid therapy: a systematic review and meta-analysis. Arch Intern Med 1999;159:941-955.

7. Martin RJ, Szefler SJ, Chinchilli VM, Kraft M, Dolovich M, Boushey HA, Cherniack RM, Craig TJ, Drazen JM, Fagan JK, Fahy JV, Fish JE, Ford JG, Israel E, Kunselman SJ, Lazarus SC, Lemanske RF Jr, Peters SP, Sorkness CA. Systemic effect comparisons of six inhaled corticosteroid preparations. Am J Respir Crit Care Med 2002;165:1377-1383.

8. Casale TB, Nelson HS, Stricker WE, Raff H, Newman KB. Suppression of hypothalamic-pituitary-adrenal axis activity with inhaled flunisolide and fluticasone propionate in adult asthma patients. Ann Allergy Asthma Immunol 2001;87:379-385.

9. Mulrennan SA, Hogg JS, Teoh RC, Morice AH. Adrenal axis suppression unrelated to the dynamics of dosing with beclomethasone monopropionate. Br J Clin Pharmacol 2007;63:288-291.

10. Allen DB. Systemic effects of inhaled corticosteroids in children. Curr Opin Pediatr 2004;16:440-444.

11. Faul JL, Tormey W, Tormey V, Burke C. High dose inhaled corticosteroids and dose dependent loss of diabetic control. BMJ 1998;317:1491.
12. Cazzola M, Boveri B, Carlucci P, Santus P, DiMarco F, Centanni S, Allegra L. Lung function improvement in smokers suffering from COPD with zafirlukast, a CysLT(1)-receptor antagonist. Pulm Pharmacol Ther 2000;13:301-305.

13. Cazzola M, Centanni S, Boveri B, Di Marco F, Santus P, Matera MG, Allegra L. Comparison of the bronchodilating effect of salmeterol and zafirlukast in combination with that of their use as single treatments in asthma and chronic obstructive pulmonary disease. Respiration 2001;68:452-459.

14. Brocco E, Velussi M, Cernigoi AM, Abaterusso C, Bruseghin M, Carraro A, Sambataro M, Piarulli F, Sfriso A, Nosadini R. Evidence of a threshold value of glycated hemoglobin to improve the course of renal function in type 2 diabetes with typical diabetic glomerulopathy. J Nephrol 2001;14:461-471.

15. Sacks DB, Bruns DE, Goldstein DE, Maclaren NK, McDonald JM, Parrott M. Guidelines and recommendations for laboratory analysis in the diagnosis and management of diabetes mellitus. Clin Chem 2002;48:436-472.

16. Woolf SH, Davidson MB, Greenfield S, Bell HS, Ganiats TG, Hagen MD, Palda VA, Rizza RA, Spann SJ. Controlling blood glucose levels in patients with type 2 diabetes mellitus. An evidence-based policy statement by the American Academy of Family Physicians and American Diabetes Association. J Fam Pract 2000;49:453-460.

17. Faul JL, Leonard CT, Burke CM, Tormey VJ, Poulter LW. Fluticasone propionate induced alterations to lung function and the immunopathology of asthma over time. Thorax 1998;53:753-761.

18. Mahmood K, Aamir AH. Glycemic control status in patients with type-2 diabetes. J Coll Physicians Surg Pak 2005; 15:323-325.

19. Kruszynska YT, Greenstone M, Home PD, Cooke NJ. Effect of high dose inhaled beclomethasone dipropionate on carbohydrate and lipid metabolism in normal subjects. Thorax 1987;42:881-884.

20. Turpeinen M, Sorva R, Juntunen-Backman K. Changes in carbohydrate and lipid metabolism in children with asthma inhaling budesonide. J Allergy Clin Immunol 1991; 88:384-389.

21. Kiviranta K, Turpeinen M. Effect of eight months of inhaled beclomethasone dipropionate and budesonide on carbohydrate metabolism in adults with asthma. Thorax 1993;48:974-978.

22. Ebden P, McNally P, Samanta A, Fancourt GJ. The effects of high dose inhaled beclomethasone dipropionate on glucose and lipid profiles in normal and diet controlled diabetic subjects. Respir Med 1989;83:289-291.

23. Jaffuel D, Demoly P, Gougat C, Balaguer P, Mautino G, Godard P, Bousquet J, Mathieu M. Transcriptional potencies of inhaled glucocorticoids. Am J Respir Crit Care Med 2000;162:57-63.

24. UK Prospective Diabetes Study (UKPDS) Group. Effect of intensive blood-glucose control with metformin on complications in overweight patients with type 2 diabetes (UKPDS 34). Lancet 1998;352:854-865.

25. Elam MB, Hunninghake DB, Davis KB, Garg R, Johnson C, Egan D, Kostis JB, Sheps DS, Brinton EA. Effect of niacin on lipid and lipoprotein levels and glycemic control in patients with diabetes and peripheral arterial disease: the ADMIT study: a randomized trial. Arterial Disease Multiple Intervention Trial. JAMA 2000;284:1263-1270.

26. The Diabetes Control and Complications Trial Research Group. The effect of intensive treatment of diabetes on the development and progression of long-term complications in insulin-dependent diabetes mellitus. N Engl J Med 1993;329:977-986. 
27. UK Prospective Diabetes Study (UKPDS) Group. Intensive blood-glucose control with sulphonylureas or insulin compared with conventional treatment and risk of complications in patients with type 2 diabetes (UKPDS 33). Lancet 1998;352:837-853.

28. Rohlfing CL, Wiedmeyer HM, Little RR, England JD, Tennill A, Goldstein DE. Defining the relationship between plasma glucose and $\mathrm{HbA}(1 \mathrm{c})$ : analysis of glucose profiles and $\mathrm{HbA}(1 \mathrm{c})$ in the Diabetes Control and Complications Trial. Diabetes Care 2002;25:275-278.

\section{AUTHOR AFFILIATIONS}

John L. Faul, MD

Department of Respiratory Medicine

Connolly Hospital

Dublin, Ireland

Sandra R. Wilson, PhD

Palo Alto Medical Foundation

Research Institute

Palo Alto, California, USA and

Division of Pulmonary and Critical Care Medicine

Stanford University

Palo Alto, California, USA

James W. Chu, MD

Division of Endocrinology and Metabolism

Stanford University School of Medicine

Palo Alto, California, USA

James Canfield, BS

Pulmonary Section

Veterans Affairs

Palo Alto Health Care System

Palo Alto, California, USA

Ware G. Kuschner, MD

Division of Pulmonary and Critical Care Medicine

Stanford University

Palo Alto, California, USA and

Pulmonary Section

Veterans Affairs

Palo Alto Health Care System

Palo Alto, California, USA 